Faculdade de Ciências Econômicas UFRGS
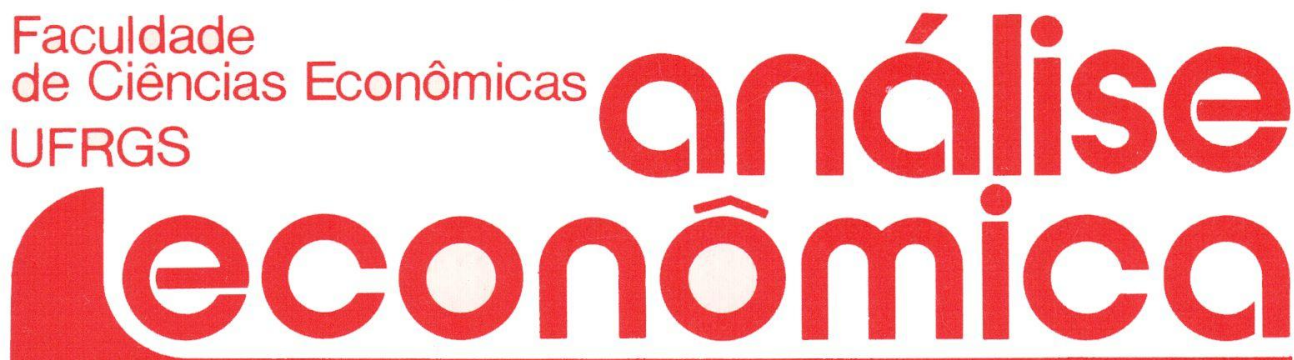

- apResentaÇ̃o à "ANálise simples da MAXIMIZAÇÂO DO BEM-ESTAR" DE FRANCIS BATOR

João Rogério Sanson

- UMA ANÁlise SIMPLES da MAXIMIZAÇÃo do BEM-ESTAR

Francis M. Bator

- O Regime de câmbio flutuante numa ETAPA DE TRANSICÃO

Francisco Eduardo Pires de Souza

- AgREgAdos monetÁRIOS, NIVEL DE RENDDA NOMINAL, TAXA DE INFLAÇÃO: UMA ANÁLISE DA CAUSALIDADE NO BRASIL, 1972 A 1987

Divanildo Triches

- A EXPlosão de CONSUMO do CRUzAdo Marcelo Cortes Neri

- METOdologia de PLANEJAMENTO do SETOR ELÉTRICO: QUESTŐES DOS ANOS 90

João Lizarolo de Araújo

Adilson de Oliveira

- CONCENTRAÇÃo INDUSTRIAL NO BRASIL SEGUNDO OS CENSOS, 1907-1980

Olimpio J. de Arrouxelas Galvão

- O VAlor, A RIQUEza e A TEORIA DE SMITH Reinaldo A. Carcanholo

- O "ESTADO ESTACIONÁRIO" e A ECONOMIa CLÁSSICA

Gentil Corazza

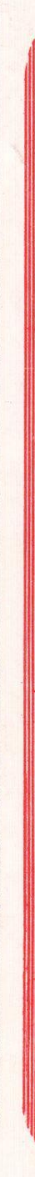
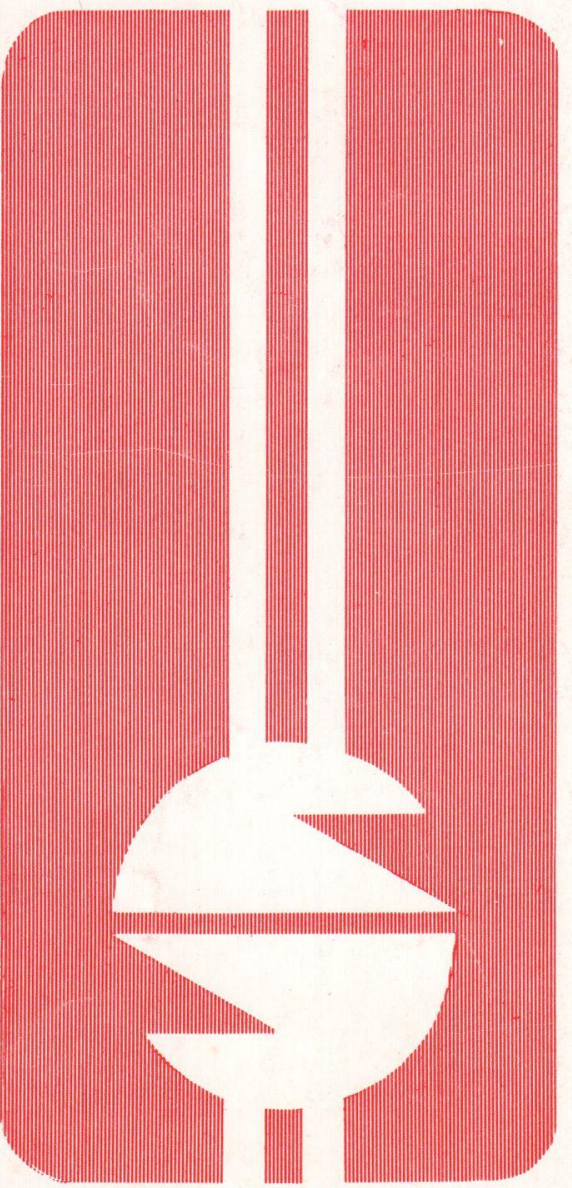
UNIVERSIDADE FEDERAL DO RIO GRANDE DO SUL

Reitor: Prof Tuiskon Dick

FACULDADE DE CIÊNCIAS ECONÔMICAS

Diretora: Prof ${ }^{\text {a }}$ Yeda Rorato Crusius

CENTRO DE ESTUDOS E PESQUISAS ECONÔMICAS

Diretor: Reinaldo Ignacio Adams

DEPARTAMENTO DE CIÊNCIAS ECONÔMICAS

Chefe: Prof. Pedro Cezar Dutra Fonseca

CURSO DE PÓS-GRADUAÇĀO EM ECONÔMIA

Coordenador: Prof. Nali de Jesus de Souza

CURSO DE PÓS-GRADUAÇĀO EM ECONOMIA RURAL

Coordenador: Prof. Atos Freitas Grawunder

CONSELHO EDITORIAL: Achyles Barcelos da Costa, Aray Miguel Feldens, Atos Freitas Grawunder, Carlos Augusto Crusius, Ernani Hickmann, João Rogério Sanson, Juvir Luiz Mattuella, Maria Imilda da Costa e Silva, Nali de Jesus de Souza, Nuno Renan Lopes de Figueiredo Pinto, Otilia Beatriz Kroeff Carrion, Otto Guilherme Konzen, Paulo Alexandre Spohr, Pedro Cezar Dutra Fonseca, Reinaldo Ignacio Adams, Roberto Camps Moraes, Valter José Stülp, Yeda Rorato Crusius, David Garlow (Wharton Econometrics Forecasts Association, E.U.A.), Edgar Augusto Lanzer (UFSC), Eleutério F. S. Prado (USP), Fernando Holanda Barbosa (FGV/RJ), Gustavo Franco (PUC/RJ), Joaquim Pinto de Andrade (UNB), Juan H. Moldau (USP), Werner Baer (Univ. de Illinois, E.U.A.)

COMISSÃO EDITORIAL: Atos Freitas Grawunder, Pedro Cezar Dutra Fonseca, Reinaldo Ignacio Adams e Roberto Camps Moraes.

EDITOR: Nali de Jesus de Souza

SECRETARIA: Maria Ivone de Mello (normalização), Vanete Ricacheski (revisão de textos), Zélide Bregalda (Secretária)

FUNDADOR: Prof. Antônio Carlos Santos Rosa

Os materiais publicados na revista Análise Econômica são de exclusiva responsabilidade dos autores. $\dot{E}$ permitida a reprodução total ou parcial dos trabalhos, desde que seja citada a fonte.

Aceita-se permuta com revista congêneres. Aceitam-se, também, livros para divulgação, elaboração de resenhas ou recensões.

Toda correspondência, material para publicaçāo (vide normas na $3^{\mathrm{a}}$ capa), assinaturas e permutas devem ser dirigidos ao seguinte destinatário:

PROF. NALI DE JESUS DE SOUZA

Revista Análise Econômica

Av. João Pessoa, 52

90.040 - PORTO ALEGRE (RS), BRASIL

Telefones: (0512) 28.1633; 24.6022; 26.0012 - Ramals 3440 e 3507

FAX: (0512) 25.5253 


\section{A EXPLOSÃO DE CONSUMO DO CRUZADO ${ }^{1}$}

\section{Marcelo Cortes Neri² \\ SINOPSE}

Este trabalho analisa algumas possiveis causas para o aquecimento de consumo, que se seguiu ao lançarnento do Plano Cruzado, principalmente no que se refere ao movimento de fuga de ativos financeiros em direçăo ao consumo observado. De início, apresentamos os principais aspectos do debate surgido em torno do tema. Posteriormente, definimos dois efeitos de realocação financeira e exacerbaçăo de consumo ligado a algurnas especificidades do processo de desinflação do Cruzado. Visamos, assim, avaliar algumas possiveis influências da inflaçăo e de poltticas de estabilização sobre as decisర̃es financeiras e de gasto das unidades familiares.

\section{INTRODUÇĀO}

Os diversos programas de estabilização de inspiração heterodoxa implantados em alguns palses da América Latina, em meados da década de oitenta, carregam dois pontos básicos comuns. A instantânea e espetacular queda das taxas de inflação e a exacerbação da demanda por bens de consumo.

Nota-se, todavia, no caso do Plano Cruzado, a presença da "explosão de consumo", tão visível a olho nu, não é tão claramente percebida nas contas nacionais. Na verdade de acordo com números mais recentes, a taxa de crescimento real do consumo pessoal em 1986 teria

1 Este trabalho corresponde a um resumo da dissertaçăo de mestrado: "Inflaçáo e Consumo: Modelos Teóricos Aplicados ao Imediato Pós-Cruzado", defendida na PUC-RJ e segunda colocada no prêmio BNDES de Economia de 1990. Gostaria de agradecer a Gustavo Franco, Sérgio Werlang, José Márcio Camargo e André Urani pelos comentários, críticas e sugestőes. Os possiveis erros remanescentes são de minha inteira responsabilidade.

2 Professor da Universidade Federal Fluminense.

\begin{tabular}{|l|l|l|l|l|}
\hline ANÅLISE ECONÔMICA & ANO 9 & № 15 & MARÇO/91 & p.97-120 \\
\hline
\end{tabular}


sido de apenas $6.2 \%$, o que, curiosamente, indicaria a menor relação consumo/renda da história das contas nacionais. No entanto, as deficiências metodológicas destes dados de consumo pessoal são bastante sérias, como o fato desta estimativa ser calculada por resíduo ${ }^{3}$ e, conseqüentemente, incorporar todos os erros e omissões presentes no sistema de contas nacionais. Resta-nos mencionar apenas que, numa economia sujeita a congelamento e excesso de demanda, como as estatísticas captam apenas o lado mais "curto" da interação entre oferta e procura as virtuais demandas dos consumidores são naturalmente subestimadas ${ }^{4}$. A despeito destes vieses, todos os índices de consume di-

TABELA 1

\section{A EXPLOSÃO DO CONSUMO DE 1986}

\begin{tabular}{|c|c|c|c|c|c|c|c|c|}
\hline & \multicolumn{5}{|c|}{ FEDERAÇĀO DO COMÉRCIO DE SÃO PAULO } & \multicolumn{3}{|c|}{ INDICES DE PRODUÇAKO (IBGE) } \\
\hline & $\begin{array}{c}\text { Indicador } \\
\text { Naclonal } \\
\text { de } \\
\text { Consumo } \\
\text { (1) }\end{array}$ & $\begin{array}{l}\text { Bens de } \\
\text { Cófisumo } \\
\text { Total } \\
\text { (2) }\end{array}$ & $\begin{array}{c}\text { Bens de } \\
\text { Consumo } \\
\text { Durávels } \\
\text { (2) }\end{array}$ & $\begin{array}{l}\text { Bens de } \\
\text { Consumo } \\
\text { Seml- } \\
\text { Durávels } \\
\text { (2) }\end{array}$ & $\begin{array}{c}\text { Bens de } \\
\text { Consumo } \\
\text { Năo- } \\
\text { Durávels } \\
\text { (2) }\end{array}$ & $\begin{array}{l}\text { Bens de } \\
\text { Consumo } \\
\text { Total } \\
\text { (3) }\end{array}$ & $\begin{array}{c}\text { Bens de } \\
\text { Consumo } \\
\text { Durávels } \\
\text { (3) }\end{array}$ & $\begin{array}{c}\text { Bens de } \\
\text { Consumo } \\
\text { Seml- } \\
\text { Durávels } \\
\text { (3) }\end{array}$ \\
\hline Nov-85 & 111,22 & 115,23 & 139,78 & 127,80 & 103,36 & 117,76 & 103,86 & 121,84 \\
\hline Dez-85 & 136,69 & 149,47 & 189,27 & 240,60 & 123,62 & 105,17 & 78,88 & 112,89 \\
\hline Jan-86 & 96,92 & 90,81 & 111,40 & 74,35 & 90,54 & 107,66 & 88,52 & 113,28 \\
\hline Fev-86 & 91,49 & 90,03 & 95,68 & 71,48 & 88,29 & 100,15 & 91,12 & 102,79 \\
\hline Mar-86 & 100,00 & 100,00 & 100,00 & 100,00 & 100,00 & 100,00 & 100,00 & 100,00 \\
\hline Abr- 86 & 114,30 & 111,24 & 124,14 & 115,75 & 99,31 & 106,05 & 103,31 & 106,84 \\
\hline Mai-86 & 124,35 & 123,01 & 155,07 & 130,00 & 108,07 & 113,66 & 110,95 & 114,45 \\
\hline Jun-86 & 118,88 & 115,29 & 136,13 & 124,96 & 98,58 & 116,84 & 108,10 & 119,40 \\
\hline Jul-86 & 133,51 & 126,23 & 157,86 & 131,54 & 110,01 & 128,28 & 99,59 & 136,71 \\
\hline Ago-86 & 126,03 & 117,84 & 158,72 & 119,63 & 115,14 & 124,87 & 100,94 & 131,90 \\
\hline Set- 86 & 137,37 & 122,84 & 159,49 & 117,98 & 116,90 & 131,81 & 119,63 & 135,65 \\
\hline Out-86 & 149,04 & 131,33 & 171,41 & 127,66 & 121,04 & 138,06 & 120,00 & 143,36 \\
\hline Nov- 86 & 142,49 & 123,04 & 176,81 & 117,95 & 125,67 & 123,02 & 99,67 & 129,89 \\
\hline Dez-86 & 176,40 & 156,96 & 248,77 & 210,11 & 149,85 & 109,70 & 80,20 & 118,37 \\
\hline
\end{tabular}

Fontes:

1 Ministério da Indústria e do Comércio

Conselho de Desenvolvimento Comercial; Notas CDC/CPE/ nºs. 06/87 e 04/88

2Federação do Comércio de São Paulo

3 Instituto Brasileiro de Geografia e Estatistica

${ }^{4}$ Clube dos Diretores Lojistas do Rio de Janeiro

3 Tendo ainda como agravante a inclusăo das variaçð̄es de estoques nas estimativas do consumo final das familias a partir de 1984.

4 Outro ponto complementar é que a difusáo das práticas de "ágio" e "caixa 2" levam inclusive a uma própria subestimativa dos efeitos niveis de produção da economia, magnificando o tamanho da chamada "Economia subterrânea". 
retamente calculados, apontam para o fantástico crescimento desta variável após o lançamento do Cruzado, tal como demonstra a tabela anterior.

O propósito deste artigo é realizar uma análise das causas da boIha de consumo surgida após o lançamento do Plano Cruzado, principalmente no que se refere ao movimento de fuga de ativos financeiros em direção ao consumo observado. Pois, no caso do Plano Cruzado, notamos não só um previsivel movimento de rernonetização da economia vinculado ao próprio processo de desinflação, como observamos também que o aquecimento da demanda de bens de consumo foi, em larga medida, financiado pela conversão de uma significativa parcela do estoque de poupança financeira previamente acumulado em consumo corrente. O plano do trabalho é o seguinte: na seção inicial faremos, uma sintese do papel desempenhado por cada um dos principais itens do plano no processo de exacerbação do consumo, procurando ressaltar alguns aspectos surgidos no debate em torno do tema. Nas seçōes seguintes, definiremos dois efeitos de aumento de consumo e de realocação financeira ligados ao próprio processo de desinflação. Na formulação destes efeitos, exploraremos num arcabouço de otimização intertemporal algumas rigidezas institucionais pertinentes ao caso brasileiro recente apresentando inclusive algumas simulações consistentes com a transição inflacionária do Cruzado. Visamos, assim, avaliar algumas possiveis influências de políticas de estabilização sobre as decisões financeiras e de gasto das unidades familiares. Algumas breves conclusões são deixadas para a última seção.

\section{OS ELEMENTOS DO CRUZADO E O AQUECIMENTO DE CONSUMO}

O Plano Cruzado representou uma tentativa de se derrubar rapidamente a taxa de inflação sem gerar grandes mudanças distributivas na economia. Em termos mais gerais, o programa de estabilização procurava reproduzir num contexto sem inflação o "status-quo" da distribuiçāo de renda observada em alta inflação. Entretanto, esta preocupação com a neutralidade distributiva ficou muita restrita à esfera da oferta da economia, na medida que o principal cuidado adotado ao se eliminar a inércia inflacionária era evitar o aparecimento de pressōes de custo 
por parte de fatores de produção prejudicados na transição inflacionária que pudessem pôr em xeque a futura estabilidade da taxa de inflaçäo5.

Uma outra caracteristica fundamental do Choque Heterodoxo era evitar o caminho indireto e doloroso das políticas de demanda contracionistas, atuando de maneira direta e incisiva sobre os mecanismos de formação de preços da economia. No entanto, a decorrente queda da curva de oferta induzida pelo Cruzado parece ter engendrado uma brusca ascensão da curva de demanda agregada da economia. Neste sentido, a forte interdependência entre as curvas de demanda e oferta agregadas, tal como defendida pelos ortodoxos se apresentaria, mas com o sinal e a direção de causalidade invertidos, pelo menos no curto prazo.

Em termos concretos, a proposta implantada em 28 de fevereiro de 1986 possui três grandes ingredientes que buscam a desinflação com neutralidade distributiva; a conversão dos salários, as "tablitas" de conversão e o congelamento de preços. Vejamos agora os possiveis papéis desempenhados por cada um destes componentes no aquecimento de consumo.

\subsection{A conversão dos salários e o "efeito-abono"}

A conversão de salários pela média real dos seis meses anteriores ao plano foi a maneira encontrada de se romper com a memória inflacionária embutida nos contratos salariais e, ao mesmo tempo, superar a brusca transferência de renda intra-salários que, inevitavelmente, aconteceria pela aplicação de uma desindexação pura e simples numa economia com forte falta de sincronização dos reajustes salariais como a brasileira no pré-Cruzado. Entretanto, no lançamento do plano, decidiuse conceder aos salários, já convertidos pela média real dos últimos seis meses, um abono da ordem de $16 \%$ ao salário mínimo e de $8 \%$ aos demais salários, o que acabou resutando num abono efetivo de aproximadamente $9 \%$ sobre o salário real médio praticado na economia. Uma primeira interpretação para a adoção deste abono seria a de tentar recompor uma parte das perdas acumuladas durante a recessão e a aceleração inflacionária da primeira metade dos anos 80 (Cichelli, 1986).

5 A condiçăo "sine-qua-non", explicitamente colocada para a implantação de um programa heterodoxo, seria a oconência de uma taxa de inflaçăo constante antes da estabilizaçăo como um sinal inequlvoco da inexistência de grupos demandantes dè ajustes de preços relativos. Af residem algumas crticas de economistas defensores da idéia do processo inflacionário como um conflito distributivo mais amplo $\theta$ instável do que o preconizado pelos inercialistas. 
Uma outra interpretação, ao invés justificar a concessão do abono salarial pela reposição de perdas salariais passadas, privilegia aspectos ligados ao futuro desenrolar do plano. Poịs além do abono salarial, o Plano Cruzado restabeleceu o princípio da anuidade dos reajustes salariais, abandonada na virada da década e introduzindo também uma cláusula de "gatilho salarial" de $20 \%$. A escala móvel funcionava teoricamente como um seguro dado aos salários contra perdas de poder de compra induzidos pelo alongamento do prazo dos reajustes de semestral para anual, caso a estabilidade dos preços não fosse realmente atingida. Desta forma, a concessão de um abono real médio ligeiramente superior a $9 \%$ aliado ao gatilho de $20 \%$ asseguraria "que, no pior dos casos, isto é, de uma inflação de $20 \%$ num prazo inferior a 12 meses, os assalariados obteriam, pós-plano, a mesma média salarial que nos seis meses anteriores ao plano" (Bacha, 1986).

Apesar destas duas justificativas acima apresentadas, existe hoje um certo consenso de que a determinação do abono não obedeceu a nenhum critério econômico especlfico, seguindo uma orientação de caráter mais político. De qualquer forma, a incidência de um abono salarial num contexto de preços congelados implica uma quebra de neutralidade distributiva, com transferência de renda entre grupos com propensōes marginais a consumir diferenciadas, induzindo a um primeiro movimento de aquecimento de consumo comumente denominado de "efeito abono".

\subsection{A "tablita" de conversão}

A tabela de conversão das obrigações contratuais futuras pré-fixadas denominadas em cruzeiro para cruzado foi uma tentativa de se evitar transferências de renda de devedores pela credores, pois as expectativas de inflação se tornariam obsoletas com a aplicação do choque, viesando fortemente para cima as suas respectivas taxas de juros reais. Por um lado, poderia-se argumentar que a taxa de inflação de $14,5 \% a$.m., embutida na "tablita" superestimaria na média as expectativas de inflação dos contratos financeiros mais antigos. Como conseqüência ocorreria uma real transferência de renda de credores para devedores, algo como um positivo "efeito-Fisher" (Kalecki, 1944) paradoxalmente associado a uma queda da inflação. Considerando, em função das maiores possibilidades de efetividade das restrições de liquidez, a propensão marginal a consumir dos devedores superior à dos credores, 
o consumo agregado sofreria uma queda. Entretanto, como a aplicação da "tablita" não foi totalmente respeitada, o efeito distributivo líquido entre credores de devedores seria na verdade bastante ambiguo.

\subsection{0 congelamento de preços}

A necessidade ou não da imposição de um congelamento de preços constituiu um importante foco de discussão entre os próprios colaboradores teóricos do plano. De um lado, estavam os defensores da aplicação de uma reforma monetária pura, conhecida em referência aos seus idealizadores como Plano Larida 6 e, de outro, estavam os defensores do congelamento dos preços como instrumento de coordenação impositiva, reconhecido como problemático, porém indispensável para a consecução de uma quebra neutra em termos distributivos da inércia inflacionária7.

Apesar do Plano Cruzado constituir uma grande simbiose das duas linhas acima descritas ${ }^{8}$, a opção pelo congelamento de preços acabou prevalecendo na sua aplicação prática. Seguramente, a adoção de um congelamento que prescindiu de um realinhamento intertemporal dos preços no momento de sua imposição agravou os naturais problemas associados a um enrijecimento do processo de fixação de preços de uma economia capitalista. A manutenção de um vetor de preços relativos "errado" desde o começo do plano aliada à própria percepção de caráter mais agregativo da necessidade de um processo de inflação corretiva da relação preços/salários, teria levado a um movimento especulativo no âmbito de consumo.

6 Ver, por exemplo, Arida e Resende (1984).

7 Ver, por exemplo, Lopes (1986).

8 Lopes (1989), lembra a presença deste caráter simbiótico nos planos Cruzado, Bresser e Austral, bem como o importante papel desempenhado pelos economistas argentinos na consecuçăo prática deste arranjo. 
Levy e Werlang (1988) abordam a impossibilidade de se congelar simultaneamente todos os preços, por conhecidos problemas de fiscalização e pela própria característica de certos produtos, como indutores de recursivos aumentos da demanda de trabalho, do salário real e, conseqüentemente, pelas tradicionais vias kaleckianas do consumo agregado. A idera é que dada a parcialidade do congelamento, a existência de início de um excesso de demanda levaria a um aumento dos salários reais e a diminuição da oferta no setor de preços congelados. Enquanto, o setor de preços livres, se inicialmente pequeno, atenderia ao aumento de demanda mais do que compensado a diminuição do primeiro setor, gerando contínuos agravamentos do excesso de demanda. De fato, o comportamento dos mercados de trabalho e de produto no ano do Cruzado foi bastante atípico. No caso do mercado de trabalho, observamos não só um fantástico ritmo de crescimento da massa real de salários, œ mo também uma forte mudança na estrutura relativa de rendimentos das diversas categorias profissionais que compōem este mercado. Esta denominada "Revolução Indesejada" do mercado de trabalho, abordada em Camargo e Ramos (1988), segundo a qual obsenva-se uma aceleração do expressivo aumento da massa real de salários, observada desde meados de 1985, e junto a isso uma inversão da estrutura relativa dos rendimentos do trabalho. Em primeiro lugar, o segmento mais organizado (trabalhadores com carteira assinada e os ligados à FIESP), que melhor defendia seus salários reais no periodo de inflação crônica, foi o que menor aumento obteve no periodo do pós-Cruzado. Certamente, este fenômeno deve ser entendido pela natural inserção destes trabalhadores em indústrias mais oligopolizadas e, portanto, mais sujeitas à efetividade do congelamento de preços. Por outro lado, a faixa intermediária composta de trabalhadores sem carteira assinada obteve significativos aumentos de seu rendimento médio, porém não tão expressivos quanto aos observados com os contra própria. Os participantes deste heterogêneo segmento do mercado de trabalho obtiveram aumentos acumulados após o plano da ordem de $58 \%$, paradoxalmente esta categoria por estar vinculada a setores mais competitivos se encontrava numa situação bastante fragilizada antes do lançamento do plano. Notem que as implicações desta "Revolução Indesejada" em termos de exacerbação de consumo é ainda amplificada pela própria diferenciação da propensão marginal a consumir entre as diversas categorias sócioprofissionais, como os dados da tabela 2, abaixo, atestam: 
TABELA 2

\section{ORDENAÇĀO DAS CATEGORIAS SÓCIO-PROFISSIONAIS POR NIVEL DE RENDA E O CONSUMO MÉDIO}

\begin{tabular}{|c|c|c|c|c|}
\hline $\begin{array}{l}\text { Runo de } \\
\text { Atulatede }\end{array}$ & Categorla Socio-Proflsalonal & $\begin{array}{l}\text { Nuvel } \\
\text { de Renda } \\
\text { Total } \\
\text { (Crs) }\end{array}$ & $\begin{array}{c}\text { Consumo Madlo } \\
\text { da Ronda } \\
\text { Total } \\
(\%)\end{array}$ & $\begin{array}{c}\text { Consumo Med } \\
\text { da Renda } \\
\text { Disponivel } \\
(\%)\end{array}$ \\
\hline 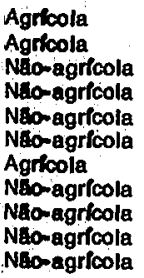 & $\begin{array}{l}\text { Empregados } \\
\text { Conta-proprla } \\
\text { Empregados manuals } \\
\text { Conta-propria estabelecidos/Outros } \\
\text { Conta proprla nâ-estabelecldos } \\
\text { Empregados nalo-manuals } \\
\text { Empregadores } \\
\text { Conta-proprla estabelecidos comerrcio } \\
\text { Empregados cargos de nkel medio } \\
\text { Empregados elou prof. llberals } \\
\text { Empregados cargos de nNel superior }\end{array}$ & $\begin{array}{r}12.550 \\
23.189 \\
25.550 \\
36.849 \\
38.244 \\
48.433 \\
54.479 \\
71.784 \\
79.064 \\
123.102 \\
167.202\end{array}$ & $\begin{array}{l}92,14 \\
79,69 \\
81,43 \\
78,24 \\
76,95 \\
74,01 \\
67,18 \\
62,12 \\
65,83 \\
61,22 \\
53,73\end{array}$ & $\begin{array}{l}93,32 \\
81,03 \\
86,70 \\
82,03 \\
81,62 \\
79,29 \\
70,24 \\
64,66 \\
71,04 \\
64,61 \\
60,75\end{array}$ \\
\hline
\end{tabular}

Fonte: Endef.

Um outro efeito de aquecimento de consumo, ligado ao congelamento de preços, seria aquele originado de movimentos especulativos na esfera do consumo numa economia congelada em excesso de demanda. Como se sabe, o desabastecimento dal advindo, traduzido sob a forma da difusão de mercados negros, ágios e filas, produziria um movimento em direção à formação de estoques de bens por produtores, intermediários e consumidores, acirrando o próprio problema da escas$\mathrm{sez}^{9}$. De fato, dados originados de uma extensa pesquisa realizada junto a consumidores de alguns centros urbanos na época do Cruzado, reportados em Singer (1988), nos dão um perfil do aquecimento de consumo e confirmam a relativa importância do congelamento ${ }^{10}$ como fator indutor de despesas de consumo não rotineiras.

\section{AS ALTERAÇÕES FINANCEIRAS}

Os principais indicadores financeiros da economia brasileira, no periodo pós-Cruzado, demonstram que a brusca mudança de comportamento observada nos mercados de trabalho e de produto estendeu-se

9 Ver, por exemplo, Kornai (1985) e Ramos (1978).

10 Certamente, à medida que "novos cruzados" săo lançados, em funçăo do normal processo de aprendizado por parte dos agentes, este componente de demanda especulativo tende a ganhar cada vez mais relevância. Por outro lado, como Franco (1988) nos chama a atençâo: "...a expectativa de uma outra intervençáo discricionária e năo neutra nos mecanismos de formaçăo de preços teminaria gerando uma inflaçăo onde comportamentos 'estratégicos' $\theta$ 'defensivos' săo dominantes". Deste modo, o congelamento do Cruzado ao abrir o precedente parece ter causado uma mudança estrutural nos comportamentos de consumidores $\theta$ firmas (A.C./D.C. (?)). 
também ao segmento financeiro da economia. Uma medida bem agregada deste ajuste está na queda de $14 \%$ observada no nível de emprego do setor financeiro entre fevereiro e outubro de 1986, conforme os dados do Ministério do Trabalho indicam. Notamos ainda, paralelamente à redução das receitas inflacionárias auferidas pelo governo e pelo sistema financeiro, também um previsível movimento de conversão de quase-moedas em moeda associado à própria queda da taxa de inflação. Este processo de remonetização pode ser captado pela desaceleração da velocidade de circulação da moeda (M1) de 28 para 13 observada nos dez meses após o plano. Agora qual a contrapartida para esta queda de receitas inflacionárias totais auferidas pelos bancos e governo11?

Em outras palavras, se uma parte do imposto inflacionário desaparece do ponto de vista de quem o recebia aonde ela reaparece? Outro ponto complementar seria quais as implicações da redução de comportarnentos defensivos antiimposto inflacionário implicito na remonetização e dos custos a eles associados sobre o poder de compra e os gastos das unidades familiares.

\subsection{0 "efeito" imposto-inflacionário e a remonetização}

Diversos autores ${ }^{12}$ realizam uma análise agregada dos impactos da taxa de inflação e do imposto inflacionário atuantes sobre os ativos monetários sobre a distribuição de renda e o nivel de demanda da economia. A idéia é que flutuações abruptas da taxa de inflação geram bruscas transferências de riqueza entre portadores e emissores de ativos monetários e, havendo uma diferenciação da propensão a gastar entre estes dois grupos de agentes, o nível de consumo e de demanda agregada seriam também logicamente afetados.

Após os sucessivos programas de choque aplicados a diversos paises da América Latina, observamos vários trabalhos de cunho microeconômico que analisaram os efeitos destas repentinas desinflaçōes

11 É importante ter em mente que a remonetização, apesar de ser incapaz de reverter a tendéncia preponderante de queda do imposto inflacionário auferido pelo governo e pelo setor bancário atua como importante fonte de fôlego financeiro destas instituiçóes, na transiçåo de uma situação de inflação crônica para a de estabilidade dos preços.

12 Ver por exemplo Diaz-Alexandro (1963), Krugman e Taylor (1978), Bacha e Lopes (1981) e Taylor (1987). 
sobre o poder de compra dos salários que se dão pela redução do impoto inflacionário ${ }^{13}$. Contudo, um importante aspecto negligenciado nestas análises seria a dinâmica de fuga e retorno aos ativos monetários respectivamente observadas em épocas de aceleração e desaceleração inflacionárias. Ou seja, devemos não só levar em conta a existência de comportamentos defensivos contra o imposto inflacionário ${ }^{14}$, mas também considerar que a difusão destes comportamentos defensivos difere para distintos patamares inflacionários observáveis numa mesma economia. Neri (1989a e 1989b) desenvolve um modelo na linha deterministica inaugurada por Baumol (1952) e Tobin (1956) no qual os agentes representativos sujeitam o número de viagens que realizam aos bancos e às lojas e, conseqüentemente, também os seus respectivos estoques de moeda, de títulos e de bens de consumo à otimização do lucro financeiro de curto prazo. O principal objetivo deste modelo é captar os impactos da inflação sobre as aplicações financeiras de curto prazo e o poder de compra de famílias de niveis de renda diferenciados. A análise procura também incorporar algumas especificidades inerentes à órbita financeira das unidades familiares e à experiência brasileira recente, a saber.

- A consideração explícita da dicotomia existente entre os bens de consumo estocáveis e os não-estocáveis como determinante dos graus de liberdade desfrutados no processe de otimização financeira individual ${ }^{15}$;

- A hipótese de imposição de uma restrição quantitativa aos títulos (contas de "overnight" e Fundos de Curto Prazo) restrição esta que se encontra vinculada ao nível de renda individual.

$\mathrm{Na}$ verdade, as alteraçōes da composição da carteira funcionam; neste modelo, como um estabilizador das mudanças do poder de compra da renda causadas pelas mudanças de patamar inflacionário. Os indivíduos de renda mais alta, por desfrutarem de acesso aos títulos de curto prazo, conseguem se proteger bastante bem dos efeitos corrosivos

13 Ver, por exemplo, Frenkel e Fanelli (1987), Modino (1987) e Oliveira Cichelli (1986). Encontramos em Ocampo (1987) um bom sumário de vários destes trabalhos.

14

Como em Modiano (op. cit.) e Oliveira e Cichelli (op.cit.).

15 Neste aspecto, o modelo representa, na verdade, um caso misto das contribuiçס̄es originais de Baumol (op. cit), onde observamos a presença exclusiva de mercadorias nåo estocáveis, e a de Feige e Parkin (1971) onde só se admite a presença de mercadorias estocáveis. 
da inflação. Desta forma, a transição inflacionária é acompanhada de uma significativa redução destes comportamentos defensivos, em contrapartida, o prejulzo (ou lucro) financeiro incorrido na administração de ativos de curto prazo pouco se altera. Em oposição, os relativamente escassos recursos de defesa antiimposto inflacionário desfrutados pelos consumidores mais pobres os força a manter parcelas de ativos monetários em alta inflação. Esta rigidez da carteira de ativos de curto prazo provoca uma grande volatilidade do poder de compra de suas baixas rendas frente a oscilações da taxa de inflação como demonstra a figura 1 abaixo:

FIGURA 1

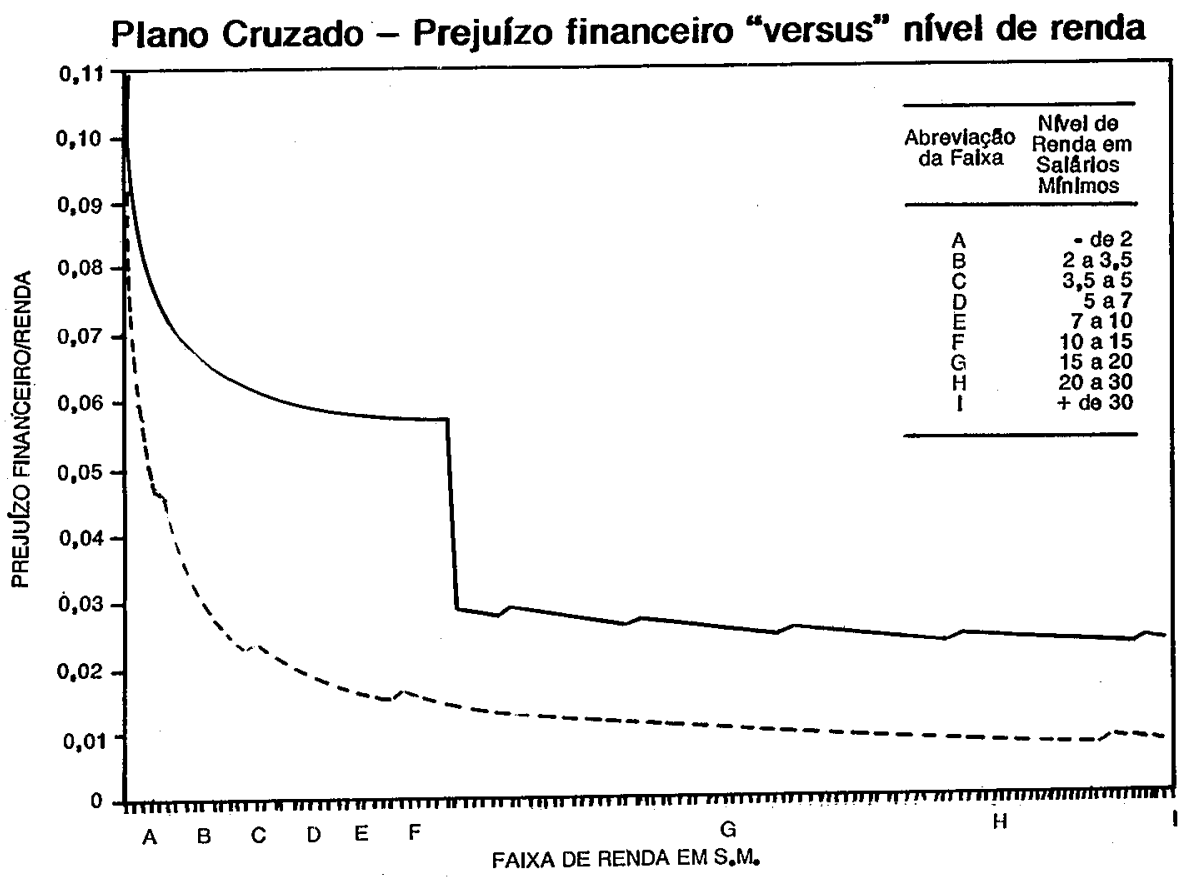

PÓS-CRUZADO

PRÉ-CRUZADO-...............-. 
A curva do prejulzo financeiro relativo de curto prazo referente à situação inflação crônica ${ }^{16}$ apresenta um grande salto no nivel de renda correspondente ao piso mínimo de acesso aos títulos ${ }^{17}$. A magnitude desta "quebra" está obviamente "condicionada ao grau de efetividade desta restrição nos valores adotados em nossa simulação à qual embutimos uma importante caracterlstica institucional presente na experiência brasileira recente, a saber a existência de sofisticadas defesas inflacionárias de ordem financeira, mais fortemente personificadas nas contas de "overnight" e fundos de curto prazo. A alta atratividade destas aplicações deve-se não só ao alto diferencial de sua taxa de retorno em relação à conferida pelos ativos monetários observado numa situação de alta inflação, mas como também aos seus baixos custos transacionais. Tal situação leva à existência de altas demandas vituais por parte dos consumidores em geral. Entretanto, a existência de altos pisos de acesso frustra a virtual demanda dos indivíduos de baixa renda, induzindo a descontinuidade na efetiva demanda por estas aplicaçōes. Em contraste, a trajetória do prejuizo financeiro referente à situação de baixa inflação apresenta um formato bem mais suave, justamente em razão da irrelevância da restrição de acesso aos títulos, num contexto de baixas taxas de juros nominais.

Em suma, partindo de um contexto inflacionário com acesso diferenciado às sofisticadas aplicações financeiras de curto prazo como o caso brasileiro contemporâneo, uma queda do patamar inflacionário induziria a um aumento do poder de compra das famílias mais fortemente sentida pelas classes mais pobres e na medida que a propensão marginal a consumir é altamente regressiva ${ }^{18}$, este efeito distributivo poten-

16 É importante ressaltar que o incremento do poder de compra dos consumidores quando a ta$x a$ de inflaçăo cal abruptamente $\&$ dado pela queda do prejulzo financeiro de curto prazo. no qual o imposto inflacionário efetivamente incorrido constitui apenas uma das partes detemlnantes. Pois, em alta inflaçăo dada, a difusăo de um custoso processo de fuga da moeda, a possivelmente baixa incidência do imposto inflacionário, pode se apresentar apenas como a "ponta de um iceberg", no que concerne às efetivas perdas impostas pela inflação às unidades familiares.

17 A negativa declividade da curva de prejulzo financeiro de curto prazo é explicada pelas conhecidas economias de escala presentes em modelos da tradiçăo Baumol-Tobin. Uma análise detalhada desta e de outras fontes da progressiva eficiência financeira das unidades familiares é encontrada no terceiro captulo de Neri (1989a.)

18 Ver Tabela 2, mais acima. Uma discussão sobre os deteminantes da regressividade da propensǎo marginal a consumir $\Theta$ feita no primeiro captulo de Neri (op.cit.). 
cializaria o aquecimento de consumo induzido pelo próprio processo de desinflação.

\subsection{0 "efeito riqueza" e a fuga da poupança}

A análise das alterações observadas no volume dos diversos agregados monetários ao longo de 1986 evidencia um certo descontrole do processo de remonetização da economia, pois além do natural aumento da participação do $\mathrm{M} 1$ no agregado mais abrangente, este último cresce cerca de $13 \%$ apenas no primeiro mês após o plano. Por outro lado, as cadernetas de poupança que não constituem substitutos próximos à moeda por excelência sofrem um brutal fluxo de retiradas no pós-Cruzado. Observamos que o fluxo de retiradas líquidas das cadernetas de poupança que vinha apresentando niveis negativos até então passa por uma violenta reversão após o plano, ocasionando uma redução da relação Depósitos de poupança/M4 de $32.3 \%$ em fevereiro para $25.8 \%$ em abril ${ }^{19}$. Complementarmente, a rica pesquisa analisada em Singer (op. cit.), nos permite analisar em detalhe microeconômico a extensão, 0 "timing" e a lógica desta alteração dos agregados financeiros, tal como as tabelas mais abaixo ilustram:

TABELA 3

APLICAÇÕES FINANCEIRAS DAS UNIDADES FAMILIARES NO PRE-CRUZADO

EM \%

\begin{tabular}{lccc}
\hline TOTAL DE FAMLIAS & SÃO PAULO & BLUMENAU & MACEIÓ \\
\hline PRATICAVAM POUANÇA EM ALGUMA FORMA & 44,5 & 53,2 & 43 \\
EM CADERNETA DE POUPANÇA APENAS & 41,9 & 50 & 40,8 \\
EM CADERNETA DE POUPANÇA & & & \\
E OUTRA FORMA & 1,5 & 2,6 & 1,8 \\
OUTRA FORMA & 1,1 & 0,6 & 0,4 \\
NÅO PRATIGAVAM POUPANÇA & 55,5 & 46,8 & 57 \\
\hline
\end{tabular}

FONTE: SINGER (1988)

19 Encontramos nas justificativas oficiais para a inclusão das cademetas de poupança na reforma monetária do Plano Collor freqüentes alusర̄es a este episódio. 
TABELA 4-A

APICAÇŐES FINANCEIRAS DAS UNIDADES FAMILIARES MUDANÇAS DO PÓS-CRUZADO

EM \%

\begin{tabular}{|c|c|c|c|}
\hline DAS FAMLLAS QUE TINHAM POUPANÇA & SÁO PALLO & BLUMENAU & MACEIÓ \\
\hline ALUMENTARAM SUAS APLICAÇŌES & 17,5 & 14 & 14,8 \\
\hline MANTIVERAM SUAS APLICAÇŐES & 35,1 & 40,2 & 31,3 \\
\hline \multicolumn{4}{|l|}{ DIMINUIRAM OU ENCERRARAM } \\
\hline SUAS APLICAÇŌES & 47,4 & 45,8 & 53,9 \\
\hline ENCERRARAM SUAS CONTAS & 23,5 & 32,2 & 37,2 \\
\hline \multicolumn{4}{|l|}{ DATA EM QUE ENCERRARAM SUAS CONTAS: } \\
\hline * MARÇO E ABRIL & 7,8 & 17,2 & 16.7 \\
\hline * MAIO E JUNHO & 6,6 & 4,5 & 7,4 \\
\hline * JULHO E AGOSTO & 3,4 & 3,4 & 3,7 \\
\hline - SETEMBRO E OUTUBRO & 1,9 & 4,9 & 5,1 \\
\hline - NOVEMBRO E DEZEMBRO & 5,8 & 4,1 & 4,7 \\
\hline • JANEIRO (1987) & 0,4 & 0,4 & - \\
\hline
\end{tabular}

TABELA 4-B

APLICAÇŌES FINANCEIRAS DAS UNIDADES FAMILIARES AS RAZŌES PARA AS MUNDANÇAS DO PÓS-CRUZADO

\begin{tabular}{|c|c|c|c|}
\hline RAZŌES & SÃO PAULO & BLUMENAU & MACEIO \\
\hline $\begin{array}{l}\text { POR QUE DIMINUIU OU } \\
\text { ENCERROU: } \\
\text { POR CAUSA DOS JUROS } \\
\text { PAGAR DIVIDA } \\
\text { GASTOS EM GERAL }\end{array}$ & $\begin{array}{r}31,4 \\
5,7 \\
85,7\end{array}$ & $\begin{array}{r}53,7 \\
4,8 \\
83,6\end{array}$ & $\begin{array}{r}65,6 \\
9,9 \\
62,7\end{array}$ \\
\hline Soma & 122,8 & 142,1 & 138,2 \\
\hline $\begin{array}{l}\text { POR QUE AUMENTOU: } \\
\text { SOBRAVA DINHEIRO } \\
\text { EMERGENCIA } \\
\text { PARA TER LUCRO } \\
\text { JUROS CRESCERAM } \\
\text { OUTRAS RAZOES }\end{array}$ & $\begin{array}{r}82,2 \\
19,4 \\
17,1 \\
7,8 \\
7,1\end{array}$ & $\begin{array}{r}68,9 \\
11,1 \\
6,7 \\
- \\
8,9\end{array}$ & $\begin{array}{r}69,4 \\
25 \\
13,9 \\
5,6 \\
13,9\end{array}$ \\
\hline Soma & 133,6 & 95,6 & 127,8 \\
\hline $\begin{array}{l}\text { POR QUE MANTEVE: } \\
\text { NAO SOBROU DINHEIRO } \\
\text { NAO PRECISOU } \\
\text { EMERGÉNCIA } \\
\text { JUROS MUITO BAIXOS } \\
\text { OUTRAS RAZOES }\end{array}$ & $\begin{array}{r}58,7 \\
34,7 \\
13,9 \\
16,2 \\
12\end{array}$ & $\begin{array}{r}27,1 \\
- \\
30,2 \\
2,3 \\
37,2\end{array}$ & $\begin{array}{l}64,5 \\
13,2 \\
21,1 \\
21,1 \\
35,2\end{array}$ \\
\hline Soma & 135,5 & 96,8 & 155,1 \\
\hline
\end{tabular}

OBS.: As respostas săo múitiplas, tendo multos declinado małs de uma resposta. FONTE: SINGER (1988) 
Nas tabelas acima, observamos que a caderneta de poupança constitue $o$ ativo financeiro mais disseminado entre as famílias brasileiras, pois mais de $94 \%$ das famílias dos três centros urbanos em questão que detinham aplicações financeiras, o faziam sob a forma de caderneta de poupança. Fatores como a falta de acesso às outras aplicaçōes, a longa tradição das cadernetas e a própria formação de hábitos financeiros familiares justificam a popularidade desta modalidade de aplicação financeira.

Nota-se, também, a partir do conjunto de motivos apresentados para a expressiva redução e encerramento das aplicações financeiras, a predominância do motivo gastos. Tal elemento confirma que os saques de poupança tiveram como fim último a aquisição de bens de consumo pelas famílias. Por outro lado, o motivo juros parece, à primeira vista, comprovar a existência de um forte componente de ilusão monetária por parte dos consurnidores ${ }^{20}$. No entanto, acreditamos na existência de alguns outros comportamentos mais inteligentes por parte das unidades familiares como indutores básicos dos movimentos financeiros e da boIha de consumo observados.

Em primeiro lugar, o tradicional mecanismo de ajuste da caderneta de poupança não isola totalmente os montantes aplicados dos efeitos corrosivos da inflação. Dada uma defasagem média de um mês e meio existente entre a efetiva alta dos preços e a automática correção monetária a taxa de juros real das cadernetas será tảo mais negativa quanto maior for a aceleração da inflação. Em outras palavras, enquanto uma inflação alta, porém estável, é inócua, a ocorrência de uma inflação inicialmente baixa, porém ascendente, é extremamente perversa quanto ao poder de compra dos recursos depositados. Num cenário de retomada inflacionária ao ritmo do pós-Cruzado (de $0 \%$ a $25 \%$ em 1 ano), observariamos uma dilapidação de cerca de $20 \%$ dos recursos inicialmente depositados.

E, finalmente, encontramos em Neri (1989a e 1989c) um possivel efeito de mudanças da taxa de inflação e dos regimes de indexação salarial sobre as decisões de gasto e de alocação financeira das familias. Vejamos o argumento: No regime de recomposição periódica de pi-

20 Testes econométricos reportados em Cysne (1988), referentes a um longo periodo de tempo, năo corroboram à hipótese de existência de ilusăo monetária por parte dos consumidores brasileiros. 
co, os salários são reajustados em intervalos regulares de forma a recuperar os seus picos de renda real corroídos pela inflação. A discrepáncia observada entre a trajetória discreta dos salários nominais vis-a-vis o contínuo crescimento dos preços introduz, porém, além da conhecida defasagem dos salários reais médios frente a choques inflacionários, também um movimento claramente descendente das trajetórias dos salários reais entre as recomposições periódicas de pico. Tal declividade parece, inclusive, ter inspirado o popular ditado segundo o qual o trabaIhador via, com o passar do tempo e o acúmulo das perdas inflacionárias incidentes sobre o seu salário fixo em termos nominais, "sobrar cada vez mais mês no fim do seu salário". O objetivo da análise é justamente abordar a adoção de comportamentos defensivos contra esta estranha situação causada pela inflação no fluxo de caixa dos trabalhadores cujos salários são indexados sob o sistema de recomposição periódica de pico. Explora-se basicamente a interação entre a inclinação negativa do fluxo de recebimento dos trabalhadores, intrínseca a este regime de indexação e o tradicional nivelamento ("smoothing") do padrão intertemporal de consumo real por parte dos agentes.

A mecânica do modelo é bastante simples: admitindo, inicialmente, um consumo mensal absolutamente constante, um estoque de poupança residual nulo e uma completa restrição de acesso a empréstimos por parte dos trabalhadores, observamos que o descompasso entre receitas e despesas do assalariado/consumidor, respectivamente captados pela inclinação negativa do fluxo de salários reais e pelo desejo de estabilidade do padrão de consumo real, gera a necessidade de transferência de poupança do início do ciclo para os meses subseqüentes. Supondo, por exemplo, um regime de recomposição semestral de pico e recebimentos mensais dos salários, o trabalhador pouparia o excedente de sua renda em relação ao nivel de consumo real desejado nos três primeiros meses do semestre visando zerar estas reservas antiinflacionárias ao longo dos três meses subseqüentes nos quais a sua renda real estivesse abaixo da média semestral). Ou seja, como o consumo mensal é regido pela renda real média semestral, a propensão marginal a poupar em relaçäo ao fluxo de renda do mesmo perlodo é decrescente ao longo do ciclo, começando em valores positivos e terminando em valores negativos. Por outro lado, o estoque de poupança acumulado ao longo do ciclo é sempre positivo e atinge o seu máximo na metade do perlodo intra-reajustes, tal como as figuras abaixo ilustram. 
FIGURA 2

Fluxo periódico de poupança como proporção da renda real de pico

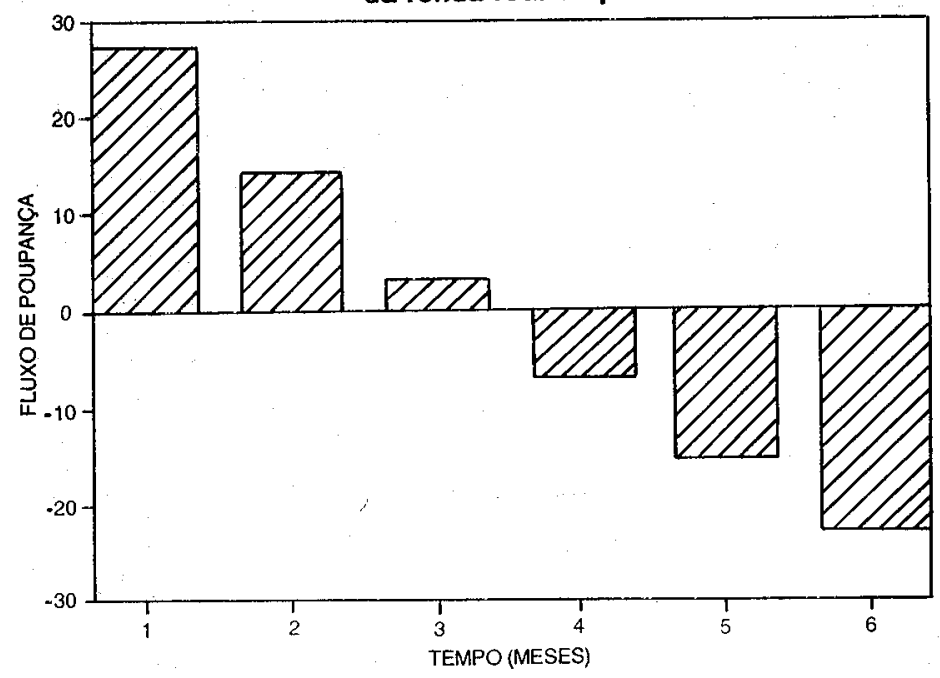

FIGURA 3

Estoque acumulado de poupança como proporção da renda real de pico

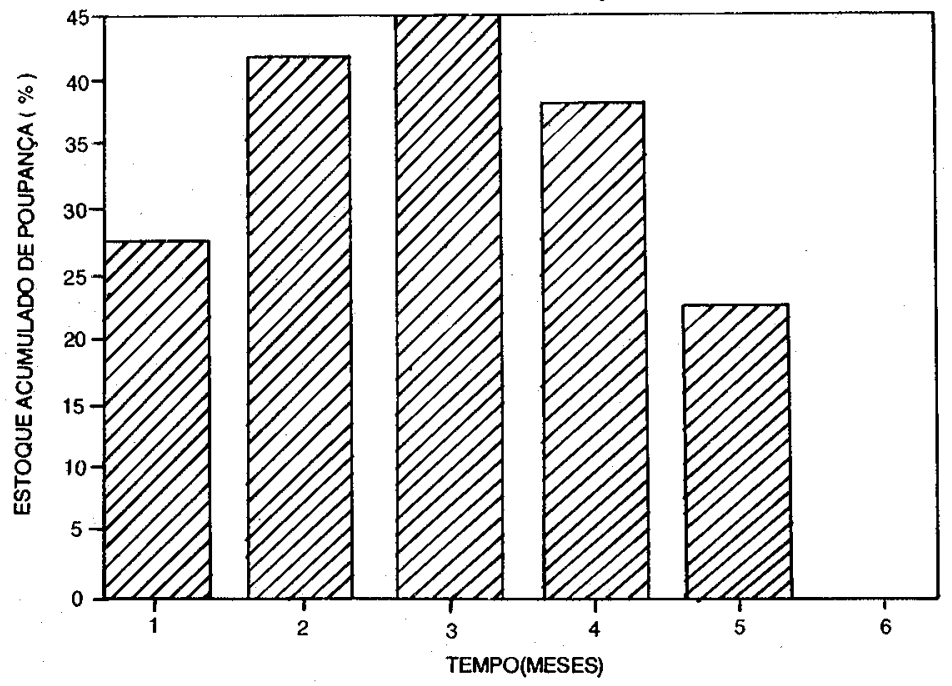


Num cenário estilizado da fase pré-Cruzado com reajustes salariais uniformemente espaçados, expectativas de taxas de juros reais nulas e de uma inflação da ordem de $15 \%$ a.m., observariamos um estoque de poupança médio acumulado entre as datas do reajuste da ordem de $41.44 \%$ do salário real médio de cada trabalhador. O resultado desta simulação acima, apesar de expressivo embute corno hipótese a uniforme da distribuição das recomposições de pico por data-base. Dados do Ministério do Trabalho, referentes ao ano de 1985, atestam, porém, uma pronunciada sazonalidade da distribuição destes reajustes ao longo do ano, como podemos notar na figura abaixo:

\section{FIGURA 4}

\section{Composição dos reajustes salariais por data-base no pre-Cruzado}

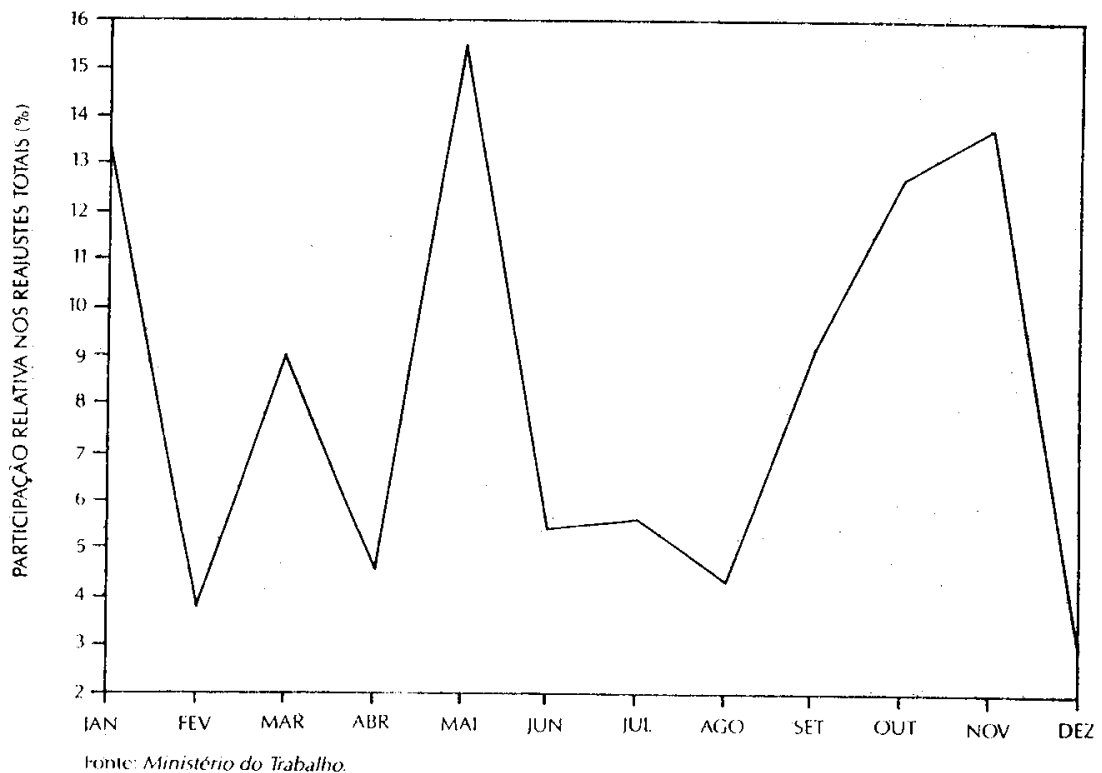

Sob esta nova distribuição dos reajustes salariais por data-base obtemos uma relação do estoque médio de poupança intra-reajustes e o salário real médio da média dos trabalhadores da economia da ordem 
de $46,59 \%$. Antes de interpretarmos o resultado desta nova simulação, é importante lembrar um importante aspecto conceitual; o salário referente ao mês de trabalho $t$ é, em via de regra, somente recebido com $o$ mês vencido, ou seja no inlcio de $t+1$. Portanto, ao calcularmos o estoque médio de poupança intra-reajustes, embutimos esta observável defasagem entre os regimes de competência e caixa dos salários nos cálculos. O significativo acréscimo da ordem de $5 \%$ em relação ao salário real médio do estoque médio de poupança do trabalhador médio da economia pode ser basicamente explicada pela alta concentraçāo das categorias com data-base em maio e novembro. Pois os trabalhadores destas especificas categorias teriam ambos recebido os seus últimos salários de pico no começo de dezembro, de forma que, em 28 de fevereiro, data de lançamento do plano, eles estariam exatamente no meio do ciclo intra-reajustes com seus respectivos estoques de poupança em seus plenos máximos.

Em termos mais genéricos, o principal resultado desta análise é que, numa economia com inflação crônica e recomposiçōes periódicas de pico numa freqüência superior a um período de recebimento de renda, os assalariados mantêm um estoque médio de poupança diretamente relacionado com a taxa de inflação e com a periodicidade dos reajustes salariais, a fim de compensar as defasagens existentes entre os fluxos de receita e despesa inerentes a este contexto. Os planos de estabilização ao tornarem obsoletas as expectativas dos trabalhadores acerca de seus fluxos salariais futuros, pelas abruptas e imprevistas mudanças de patamar inflacionário e das próprias regras de indexação salarial, tenderiam a produzir uma violenta alteração nos níveis desejados destes estoques de poupança intra-reajustes. No caso especifico do Cruzado, tanto a repentina desinflação causada pelo congelamento e eliminação de memória inflacionária dos contratos, quanto o aumento do grau de indexação salarial, ocasionado pela troca das recomposições semestrais pelo gatilho de $20 \%$, contribulram para a ociosidade deste estoque de poupança intra-reajustes, herdado da fase cronicamiente inflacionária, provocando a exacerbação do consumo21.

21 E importante ter em mente que este replanejamento dos estoques de poupança intra-reajustes constitue um "efeito riqueza", no sentido de aumentar a renda permanente para horizontes de tempo finitos, dado aos agentes de forma liquida.

Outro momento de forte aquecimento de consumo de nossa história económica recente que pode ser também pensado a partir deste replanejamento da poupança intra-reajustes seria o ocorrido ap6́s a reduçåo da periodicidade dos reajustes salariais de anual para semestral em finais de 1979. 
Em suma, exploramos uma possivel dimensảo das influências do binómio inflação-indexação sobre as decisōes de gasto e de demanda por ativos financeiros dos assalariados. Desta forma, elaborou-se uma visão alternativa a fatores como incerteza e ilusão monetária na análise da relação entre inflação, órbita financeira e consumo. Uma possivel extensăo da análise seria justamente a introdução destes fatores no ámbito do modelo. No entanto, chamamos a atenção para o fato de que a força do argumento reside justamente em explicar a existência de um estoque de poupança financeira positivo ligado a um processo de inflacionário puramente inercial, sem precisar lançar mão de incertezas ou mesmo de qualquer comportamento equivocado por parte dos consumidores.

\section{Conclusōes}

Na implantação do Plano Cruzado podemos dizer que os seus idealizadores atiraram e acertaram no que viram, ou seja, efetivamente desinflacionaram intantaneamente a economia, mas foram atingidos pelo que não viram, ou seja, pelo surgimento de uma inesperada e explosiva exacerbação da demanda, em especial a de consumo, e de sua conseqüente pressão sobre o nivel geral de preços que veio pouco a pouco a erodir o sucesso inicial do programa de estabilização. Como lembra Carneiro (1987), "os críticos de primeira hora descarregaram suas baterias contra o aspecto recessivo do programa”, enquanto na percepção dos idealizadores do plano, apesar de uma certa consciência quanto à sua não estrita neutralidade, os efeitos finais do elenco de medidas adotado sobre a distribuição de renda e a demanda agregada foram claramente subestimados.

Sustentamos que, embora uma significativa parcela do aumento de demanda verificado pudesse ser creditada à adoção de políticas mo-netárias ${ }^{22}$ e fiscais ${ }^{23}$ expansionistas, uma grande parte do aumento de consumo se deveu à operação de mecanismos endógenos não contemplados no programa de pesquisa que originou nos concretos planos de combate a inflação de natureza heterodoxa. Dentro de uma perspectiva de demanda, analisamos a explosão de consumo de 1986 a partir de

22 Ver, por exemplo, Bodin (1989).

23 Ver, por exemplo, Cysne (1988). 
algumas não neutralidades do Plano Cruzado. As nossas principais conclusōes são as seguintes:

Apesar de todo o aparato teórico, que deu respaldo ao Cruzado, ter sido basicamente voltado para neutralizar mudanças redistributivas intra-salários, intralucros e entre salários e lucros; a concessão do abono salarial aliada à estrutural mudança observada na determinação do salário real e do nivel de consumo numa economia sujeita a congelamento atuaram como importantes propulsores da bolha de consumo em questão.

Posteriormente, exploramos através da alta regressividade do "Efeito Imposto-Inflacionário" a contrapartida financeira de curto prazo da idéia de Belinda de Edmar Bacha, onde a fronteira entre a parte belga e $a$ indiana se daria no piso mínimo de acesso às sofisticadas aplicaçöes financeiras de curto prazo. Deste modo, corroboramos à versão oficial de que "o Plano Cruzado incorporou novos agentes ao mercado consumidor" que corresponderiam, no estrito escopo deste modelo, à massa de individuos excluídos da órbita financeira de curto prazo da economia brasileira.

E, finalmente, analisamos, a partir de especificidades institucionais inerentes à experiência brasileira recente, uma linha de racionalização para a relaçāo existente entre demanda por ativos financeiros, de um lado, e taxa de inflação/periodicidade entre os reajustes salariais, de outro. Possibilitando, desta forma, entender a partir de um "efeito-riqueza" engendrado pela desinflação e pela reindexação salarial do Plano Cruzado, o brusco movimento de fuga das cadernetas de poupança em direção à aquisição de bens de consumo observado.

\section{BIBLIOGRAFIA}

ARIDA, Pérsio \& RESENDE, André Lara. Inercial Inflation and Monetary Reform in Brazil. Rio de Janeiro, Departamento de Economia da PUC/RJ. 1984. (Texto dara Discussão n.85).

BACHA, Edmar L. \& LOPES, Francisco P. Inflation, Growth and Wage

Policy: In Search of a Brazilian Paradigm. Journal of Development Economics. Sept. 1981.

- A Inércia e o Conflito: O Plano Cruzado e seus Desafios. Rio de Janeiro, Departamento de Economia da PUC/RJ, 1986. (Texto para Discussão n. 131).

BAUMOL, W.J. The Transaction Demand for Cash, an Inventory Theore- 
tic Approach. Quarterly Journal of Economics. Nov. 1952.

CAMARGO, J.M. \& RAMOS, C.A. A Revolução Indesejada. Rio de Janeiro, Campus, 1988.

CARNEIRO, D.D. Heterodoxia e Política Monetária. Rio de Janeiro, Departamento de Economia da PUC/RJ, 1988. (Texto para Discussão n.179).

CICHELLI. R.V. Exacerbação do Consumo e Salário Medio: Evidências Sobre o Efeito Sincronizaçāo. Rio de Janeiro, IPEAINPES, 1986. (Texto para Discussão n.95).

CYSNE, R.P. Plano Cruzado: Erro de Concepção e de Polltica Fiscal. In: BARBOSA, Fernando $H$. \& SIMONSEN, Mario $H$. (orgs.). Inércia e Inépcia. Rio de Janeiro, Globo, 1988.

- Monetary Correction and the Real Interest Accounting. Rio de Janeiro, EPGE/FGV, 1988b.

DIAZ, Alexandro, C.F. A Note on the impact of Devaluation and the Redistributive Effect. Journal of Political Economy. v.71, n.6, 1963.

FEIGE, E.L. \& PARKIN, M. The Optimal Quantity of Money, Bonds, Comodity Inventories and Capital. American Economic Review, v.LXI, n.3, June 1971, p.335-49.

FIBGE. Estudo Nacional das Despesas Familiares 1974-75 para a Regiảo Metropolitana de São Paulo (ENDEF), Rio de Janeiro, IBGE, 1978.

FRANCO, Gustavo H.B. Inflaçāo e Abertura. Rio de Janeiro, Departamento de Economia da PUC/RJ, 1988, mimeo.

- Inércia e Coordenação, Pactos, Congelamento e seus Problemas. Pesquisa e Planejamento Económico. v.19, n.1, abr. 1989.

FRENKEL, Roberto \& FANELLI, José Maria. El Plan Austral: Un Año y Medio Después. El Trimestre Económico, n. especial, set. 1987.

KALECKI, M. Professor Pigou on "The Stationary Stade": A Comment. Economic Journal, Apr. 1944.

KORNAI, J. Economics of Shortage. Amsterdam, North Holand, 1985. KRUGMAN, Paul \& TAYLOR, Lance. Contractionary Effects of Devaluation. Journal of International Economics, v.8, 1978.

LEVY, J.F. \& WERLANG, S.C. Congelamento com Abono Salarial, Gerando Excesso de Demanda. In: BARBOSA, Fernando H. \& SIMONSEN, Mario H. op. cit, 1988.

LOPES, Francisco P. Só um Choque Heterodoxo Pode Derrubar a Inflação. In: - O Choque Heterodoxo, Rio de Janeiro, Campus, 1986. 
O Desafio da Hiperinflaçāo em Busca da Moeda

Reał Rio de Janeiro, Campus, 1989.

MODIANO, E. Repasses Mensais x Reajustes Trimestrais. Rio de Janeiro. Departamento de Economia da PUC-RJ, (Texto para Discussão, n.180).

MORAES, P.B. A Conduçâo da Política Monetária Durante o Pla-

no Cruzado. Rio de Janeiro, Departamento de Economia da PUC/RJ, 1988. (Texto para Discussão n:200)

NERI, Marcelo C. Inflação e Consumo: Modelos Teóricos Aplicados ao Pós-Cruzado. Rio de Janeiro, Departamento de Economia da PUC/RJ, 1989, Dissert. (mestr. econ.), PUC/RJ.

- . Inflação, Reindexação Salarial e Aquecimento do Consumo: uma Nova Perspectiva. In: ENCONTRO NACIONAL DE ECONOMIA, 17, Fortaleza, 1989. Anais... São Paulo, ANPEC, 1989c. v.1, p.57-72. - O Imposto Inflacionário e o Poder de Compra das Unidades Familiares: Um Modelo Aplicado aos Planos Cruzado e Verão. In: ENCONTRO NACIONAL DE ECONOMIA, 17, Fortaleza, 1989. Anais... São Paulo, ANPEC, 1989b, v.2, p.955-75.

OCAMPO, J.A. Una Evolución Comparativa de Cuatro Planes Anti-Inflacionarios Recientes, Fedesarollo, Bogotá, 1987.

OLIVEIRA, D.A.R. \& CICHELLI, R.V. O Programa de Estabilizaçăo Económica e o Poder de Compra do Salário Mínima. Rio de Janeiro, IPEAIINPES, out. 1986. (Texto para Discussão n.97).

RAMOS, J. Inflacion Persistente, Inflacion Reprimida e Hiperestanflacion: Lecciones de Inflacion y Stabilizacion en Chile. Desarrollo Económico.v.69, abr. 1978.

SINGER, Paul. Os Impactos do Plano Cruzado sobre Renda, Emprego, Poupança e Consumo. São Paulo, CEBRAP, 1988, mimeo. TOBIN, J. The Interest Elasticity of Transactions Demand for Cash. Review of Economics and Statistics, Aug. 1956.

TAYLOR, L. A Structuralist Analysis of Inflation and Stabilization. MIT, 1987, mimeo.

\section{ABSTRACT}

\section{THE CRUZADO’S CONSUMPTION EXPLOSION}

This paper discusses some possible causes of the increase in consumption which followed the Cruzado Plan launching, specially as it relates to the observed substitution of consumption for financial assets. 
Firstly, it makes an exposition of the main aspects in the debate which arose over the subject. After that two allocative effects are defined which are linked to the increase in consumption and some particularities in the desinflation process of the Cruzado. The paper tries to evaluate some possible influences of inflation and stabilization policies on financial and expenditure decisions made by households. 